\title{
LA JUSTICIA
}

\author{
REMY LLERENA, Gaston ${ }^{215}$
}

\author{
"Un eterno \\ recuerdo permanecerá \\ del hombre justo " \\ Tehilim (Salmos) 112,6
}

La Historia Universal nos presenta a grandes pensadores, filósofos, juristas, teólogos, sociólogos, de distintas nacionalidades y en épocas diversas, que han expresado propias ideas respecto de la Justicia, a veces coincidiendo y sumando seguidores; otras veces discrepando acerca de ella y del modo de lograrla. Se han propuesto diversas clases de Justicia y modos de realizarla. Se entiende que su logro abarcaría a cada miembro componente de un grupo social determinado (con la esperanza de extenderse a todos los grupos humanos) En resumen, cada persona realizando actos justos, lo que implicaría realizar la Justicia por todos y para todos.

Nadie quedaría excluido de la Justicia, como un "bien común" concertado que rechaza todo lo que pudiera afectar, de cualquier modo, a alguno de derechos o intereses propios de la dignidad del hombre.

Lo cierto es, que, milenios después de continuas propuestas, seguimos en la búsqueda de la mejor idea y realización de la Justicia.

Mi idea acerca de la Justicia se basa en la experiencia de vida; mirando mi entorno, por décadas, que son muchas en mi vida; miradas al desenvolvimiento de los grupos humanos con los que libre u obligadamente he debido relacionarme por razones familiares, de estudios, laborales públicos y privados, organizaciones sociales y de gremio profesional y otros espacios de desenvolvimiento personal.

No es tan importante saber si la justicia se identifica con la igualdad, proporcionalidad, armonía, medida de cambio o distribución o como valor jurídico.

La Justicia sigue siendo una utopía porque no todos los hombres nos esmeramos en ser proactivos con nuestros prójimos; nos domina el egoísmo deseando recibir solo para nosotros sin ánimo de compartir. No nos preocupamos si los demás obtienen aquellos bienes espirituales y materiales que satisfagan las múltiples necesidades comunes. Sin desearlo realmente hemos ingresado, subterráneamente, movidos por intereses de grupos de poder, desde muchísimo tiempo atrás, en un mundo en el que todo se mueve en base a la competencia que nos determina a imponernos sobre los demás, en todos los campos posibles de actuación. Simplemente se trata de ganar, vencer a los demás, para lograr tener lo que

${ }^{215}$ Abogado y docente de la Facultad de Derecho y Ciencia Política de la Universidad Ricardo Palma. Miembro de la Comisión encargada del Funcionamiento de la Facultad de Derecho y Ciencia Política de la URP. 
ansiamos a costa de los otros. Se impone el "ego" sobre los "otros". Se ignora la esencia común.

Esa competencia mueve a los hombres, para prevalecer sobre los demás, sin interesarnos los medios empleados-buenos o malos-para lograr esa supremacía. Este mundo dentro del cual se desarrolla esa dañina competencia inducida, nos determina a restar importancia a las carencias de distinto orden que afectan a nuestros prójimos, ausencias denigrantes de la condición humana, afectantes de su condición de personas con derechos inherentes propios a su dignidad, a su libertad, al reconocimiento de su desarrollo vital e integridad moral, psíquica y física y a su libre desarrollo y bienestar, como declara la "letra mиerta" del artículo $1^{\circ}$ de nuestra Constitución en vigencia.

Considero que es justo desear y realizar dentro de nuestras posibilidades materiales y espirituales (morales, si es preferible el término para algunos) todo el bien para nosotros, pero haciéndolos extensivos a los demás; y estos deseando y realizando dentro de similares posibilidades iguales bienes para sí mismos como para los demás.

La Justicia no debe ser letra muerta, que exprese solo ideales o deseos, sino actuación permanente para que sea concreta, real, visible. Pienso que la Justicia es comportamiento de todos para el bien de todos. Todos actuando por el bien común. Como hace poco expresara el señor presidente de la República de Uruguay, don José Mujica, después de su entrevista con el actual Papa, palabras más palabras menos: "Hay que pensar con calor militante, de compromiso en la lucha contra la pobreza para eliminar las diferencias sociales". Es que en una sociedad justa no deben existir diferencias sociales sustentadas en la desigual distribución de la riqueza. En la sociedad justa participan activamente, para su concretización, el Estado, la Sociedad civil organizada, además de la participación activa de cada uno y todos los individuos que la conforman. En la sociedad justa que deseamos debe desaparecer el poder manifiesto u oculto a veces, para el que resulta insignificante la pobreza de los menos favorecidos. Pobreza es sinónimo de injusticia. Como afirma Gustavo Gutiérrez en su obra "Teología de la Liberación":

"La pobreza significa en última instancia, muerte. Carencia de alimento y de techo, imposibilidad de atender debidamente a necesidades de salud y educación, explotación del trabajo, desempleo permanente, falta de respeto a la dignidad humana e injustas limitaciones a la libertad personal, en los campos de la expresión, lo político y lo religioso, sufrimiento diario".

Para Amartya Sen, profesor en Harvard, premio Nobel de Economía, la justicia, no solo es un problema de orden filosófico, lo es también de práctica social. Pretende la concretización de la justicia, cuando afirma:

"Lo que nos mueve, con razón suficiente, no es la percepción de que el mundo no es justo del todo, lo cual pocos esperamos, sino que hay injusticias claramente remediables en nuestro entorno que queremos suprimir"

El profesor de Harvard no se preocupa tanto por la naturaleza de la justicia perfecta; parece que opta por un Estado ético, que abandone la corrupción y la ineficiencia, que asuma políticas económicas y de administración gubernamental que realmente permitan atender la pobreza material- evidente manifestación de injusticia-especialmente en países tercermundistas eufemísticamente denominados países en vías de desarrollo. 
Desde esa óptica, consideramos que el Estado y los gobernantes de turno cuyas ideologías triunfan temporalmente frente a ideologías opositoras en auténticos procesos electorales (excluyo las farsas electorales) siendo legitimados por el pueblo, para actuar en su nombre, representándolo ordinariamente, deben tener verdadero ánimo de cumplir su parte en este contrato social asumido con la población, de servir y cumplir a cabalidad los enunciados constitucionales respecto de los derechos humanos, políticos, sociales y económicos de las personas. A través del Estado, el gobierno debe ser expresión de la voluntad común representativa, no ejerciendo un poder propio, sino comisionado por el pueblo con propósito de lograr el bien común.

Sabemos de la imposibilidad de que en tan corto periodo de gobierno, pueda lograrse; pero deben iniciarse estas concretizaciones de la Justicia, para eliminar la pobreza que vemos creciente en nuestras calles. Madres, niños, ancianos, discapacitados, enfermos mentales, drogadictos, todos totalmente desvalidos, intentando subsistir y pidiendo de mil maneras solución a sus carencias, todas. El enunciado de políticas exige planes de gobierno efectivos, que conduzcan a la disminución progresiva hasta el total agotamiento de esos males, en caso de no poder lograr su pronta eliminación.

El Estado debe realizar verdadera redistribución de la riqueza, con mayor imposición tributaria a los que más lucran, para poder desarrollar programas de salud y educación. Realizar promoción empresarial que genere nuevos puestos de trabajo para acabar progresivamente con la desocupación, haciendo realidad el trabajo como derecho y deber del ciudadano, base del bienestar social y medio de realización de la persona. Esa promoción empresarial pública, a la par de la privada existente; y, si esta fuera insuficiente porque no conviene a sus intereses invertir haciendo empresas, debe ser creciente la actividad empresarial pública, sin importar la vieja expresión interesada de que la empresa estatal es deficiente y generadora de pérdidas, cuando vemos a cada momento como quiebran las empresas privadas por pésima o dolosa gestión. Basta recordar la reciente crisis financiera mundial generada por el sector privado, para no hacer caso a la desinformación sobre la actividad empresarial del Estado. Por el contrario, en esa crisis mundial a la que hemos aludido, los gobiernos de los Estados han apoyado a los empresarios privados, proporcionándoles miles de millones de dólares o euros, "socializando pérdidas", sin tener en cuenta que ellos, los empresarios, no socializan sus utilidades obtenidas, por el contrario las individualizan según propios y proporcionales aportes, asumiendo exclusiva y egoístamente esos beneficios económicos, porque, afirman, "arriesgan su inversión, solos". Ignorando la esencial y por ende muy importante participación del trabajo en la producción empresarial de bienes para su comercialización o prestación de servicios. Les parece o son convictos de que solo su dinero organiza y desarrolla la empresa.

La sociedad civil organizada, integrada por grupos concretos de interés, tratando de expresarse unitariamente frente a los problemas de injusticia social, apoyando al Estado en la promoción del desarrollo social que abarca lo cultural, económico, político y jurídico. Colaborando y exigiendo al Estado mayor presupuesto anual para la educación, pues siendo creciente la inversión en ella, será decreciente la dependencia de sus beneficiarios. También invertir en programas de salud que sean extensivos a todos los peruanos, a fin de evitar comprobaciones como la realizada por la Defensoría del Pueblo, expuesta en el Informe Defensorial $\mathrm{N}^{\circ} 161$ "Camino al Aseguramiento Universal en Salud: resultados de la supervisión nacional a hospitales": 
"Los hospitales ubicados en la regiones, y en particular los que pertenecen a los gobiernos regionales, son los que presentan mayores carencias y dificultades, marcando una clara inequidad en salud, que el Estado se encuentra en la obligación de revertir".

Servicios educativos y de salud, de seguridad ciudadana y otros, que no lleguen solo a ciudades principales; acercándose también a los rincones más apartados del país donde el Estado antes no arribó. Pues todos, sin excepción, tenemos iguales derechos. El sistema jurídico partiendo desde el Estado, no debe enunciar derechos solo para unos cuantos, pues se caracteriza por su generalidad de aplicación, salvo mínimas excepciones. En resumen, respetando la dignidad de la persona como fin en sí misma, posibilitando calidad de vida a todos, sin excepción, pues esa dignidad no es ajena a quien no contribuyó o contribuyó menos que otro, sin importar razones, al buen desenvolvimiento social. Ser persona es suficiente razón para que el Estado, la sociedad, cada uno de nosotros, reconozcamos su dignidad como atributo connatural inherente, que nos identifica como iguales.

Desconocer dignidad a otros implica desconocer la propia dignidad.

Cuando todas las personas o notoriamente mayoritaria la población y sus estructuras político-jurídicas, sean actuantes por la Justicia, en los términos sencillamente expuestos sin grandilocuencias ni academicismos, no será tan importante ni tendrá mayor valor la definición de justicia, pues la entendemos en fuero interno como solidaridad tangible con el prójimo, sin pretensiones egoístas del propio beneficio atentatorio del bien común que socava la vida social. Esta convicción, producto de nuestra participación activa en y para la comunidad, será suficiente para nuestra paz espiritual, pues sabremos que caminamos por las vías que nos conducen al mundo del bien común, en el que incluso aquellos que están incapacitados para aportar su grano de arena para la realización de la Justicia, tengan todos sus derechos no solo reconocidos, también otorgados sin discriminación alguna.

La utopía dejará de ser tal, cuando todos caminemos en el sendero que conduce al paraíso buscado, hace milenios, de la Justicia y el bien común.

"Aprendan a hacer el Bien busquen Justicia y sustenten al oprimido. Exijan Justicia para el huérfano y defiendan la causa de la viuda" Toráh, Ieshaiá (Isaías) 17. 